Project presentation

\title{
Training, Consulting and Teaching for Sustainable Approach for developing Research Data Life-Cycle Management expertise in Switzerland
}

\author{
Basma Makhlouf-Shabou \\ Information Science Dept. // Geneva School of Business Administration, \\ University of Applied Sciences and Arts Western Switzerland \\ Rue de la Tambourine 17, Bât. B, 1227 Carouge, Switzerland \\ basma.makhlouf-shabou@hesge.ch
}

\begin{abstract}
Summary
Developing research in different fields is defendable as well as necessary for the development of disciplines and knowledge construction in general. The progress of qualitative and quantitative approaches is based on hard competitiveness and high level of innovation. This increases the need of a rigorous management of research process which should be more and more accurate and traceable to ensure a good data management approach. Considering this context, European Council stipulates a directive to require a good research data management in order to reinforce the ability of researchers to conduct properly their research activities (European Commission, 2016). For example the H2020 projects requires a Data Management Plan (DMP) since January 2017. In Switzerland, this tendency was clearly confirmed. Swiss researchers have been submitting their proposals to funding agencies without any requirement for research data management so far. However, the Swiss National Science Foundation will require a DMP since October 2017. Researchers are not prepared. They don't know how it impacts their work and are looking for solutions to comply with these new requirements. This paper draws a general portrait of a recent Swiss project on this subject: data life cycle management applied on research data: DLCM ${ }^{1}$. It presents, first, an over view of the main objectives and major dimensions of DLCM project and second, it will focus on one those latest which is dealing with training, consulting and teaching in the field of research data management.
\end{abstract}

Key words: research data, national services, research data life cycle management, data governance, research data training, research data consulting

\footnotetext{
${ }^{1}$ https://www.dlcm.ch/
} 


\section{Introduction}

We understand the notion of research data governance as a global and exhaustive management of data arising from the research process in order to guarantee its use, security and optimization, from its creation and capture to its disposal (UK Data Archive, 2017). In the Swiss context, the research data management should be studied considering two levels: cantonal and federal. Regarding the cantonal level, public universities and high schools are mainly managed by the 26 cantonal government. The federal level concerns especially the seven federal administration's departments and is not synonymous of national level, under which the federal institutes of technology or "polytechnics" are supervised. Added to those main two levels, we have thus a third-level: an inter-cantonal level that proposes a network of high schools in different cantons of Switzerland as well as the University of Applied Sciences and Arts of Western Switzerland. The data management issue affects all levels (cantonal, inter-cantonal and federal), and also the public and private sectors, like academic institutions or private laboratories. Despite this particular fragmented environment, researchers needs remain generally comparable. The issues related to the various aspects of research data processing remain the same (DMP designing, security of sensitive data, long-term preservation, etc.). In addition, some technical solutions are very expensive and require a specialized expertise. In this context, the idea of national services was argued and some initiatives were encouraged in order to develop national solutions to enhance Swiss researchers developing such expertise and share their resources to comply with standards and good practices as well. In this same context, openness and sharing research data has become essential to obtaining funding for research projects. The DLCM Project is one of those initiatives which aiming to provide scientific communities a research data national services. It started at the end of 2015, and is funded by the RCSU (Rectors'Conference of the Swiss Universities) and is conducted under the leadership of the University of Geneva, especially the Information system service. It should finish in 2018. The following sections will first specify the objectives of the project after a brief presentation researcher's needs. Second, the dimension of training, consulting and teaching in the field of research data management will be presented.

\section{Initial exploration of the needs}

As mentioned, the research need examination was the starting point for the project to be able to design accurately its main deliverables. To do so, an explorative approach was adopted. Based on a series of semi-structured interviews with some 50 researchers and heads of research departments working in some thirty disciplines at six institutions, we were able to identify mainly four ranges of needs. 
B. Makhlouf-Shabou The Research Data Life-Cycle Management in Switzerland

1. The first are guidelines and tools. There is a lack of practical guidance. When we talk about guidelines, policies or management programs, we mainly think of tools such as the DMP (Data Management Plan), the tools of analysis, coding of the information or the collected data, and all that is related to the preservation and publication. This includes also, research data governance policies.

2. The second is all that concerns the processing of information in the first phase of the research process, before reaching the preservation and the disposal. It refers to processes, tools, methods and best practices needed to active data management.

3. The third is about the management of the collected data, the results and the publications, including the reuse and sharing of research data, in particular it's various modes and channels.

4. Finally, the qualified staff, which has a dedicated expertise, developed especially in the management of research data, also represents something that is missing. Generally, the universities do not have an important staff of archivists or records managers. And the focal point into universities became the librarian who has certain knowledge of this domain. However, this later remains not sufficiently prepared to assume this role because his professional profile as a librarian does not allow him to provide appropriate and advanced expertise needed or requested by researchers.

\section{Objectives and deliverables}

Based on need analysis, the project objectives are focused around five fields:

1. Guidelines \& Policies - key tools commonly used and recognised at an international level;

2. Active Data Management - everything linked with the records management;

3. Publication \& Preservation - the perpetuation and the publication for a future reuse;

4. Consulting and Training - the perpetuation and the knowledge transfer in this field;

5. Outreach \& Dissemination - the publication and the promotion of everything that will be developed in the context of the project.

To do so, the implementation of DLCM project was articulated on 6 main tracks (dimensions) as shown in Figure 1:0) project management; 1) guidelines and policies, 2) active data management; 3) publication and preservation (Burgi, Blumer and Jelicic, 2017); 4) training and consulting; 5) dissemination publication (Makhlouf Shabou, Burgi, Blumer and Echernier, 2016). 


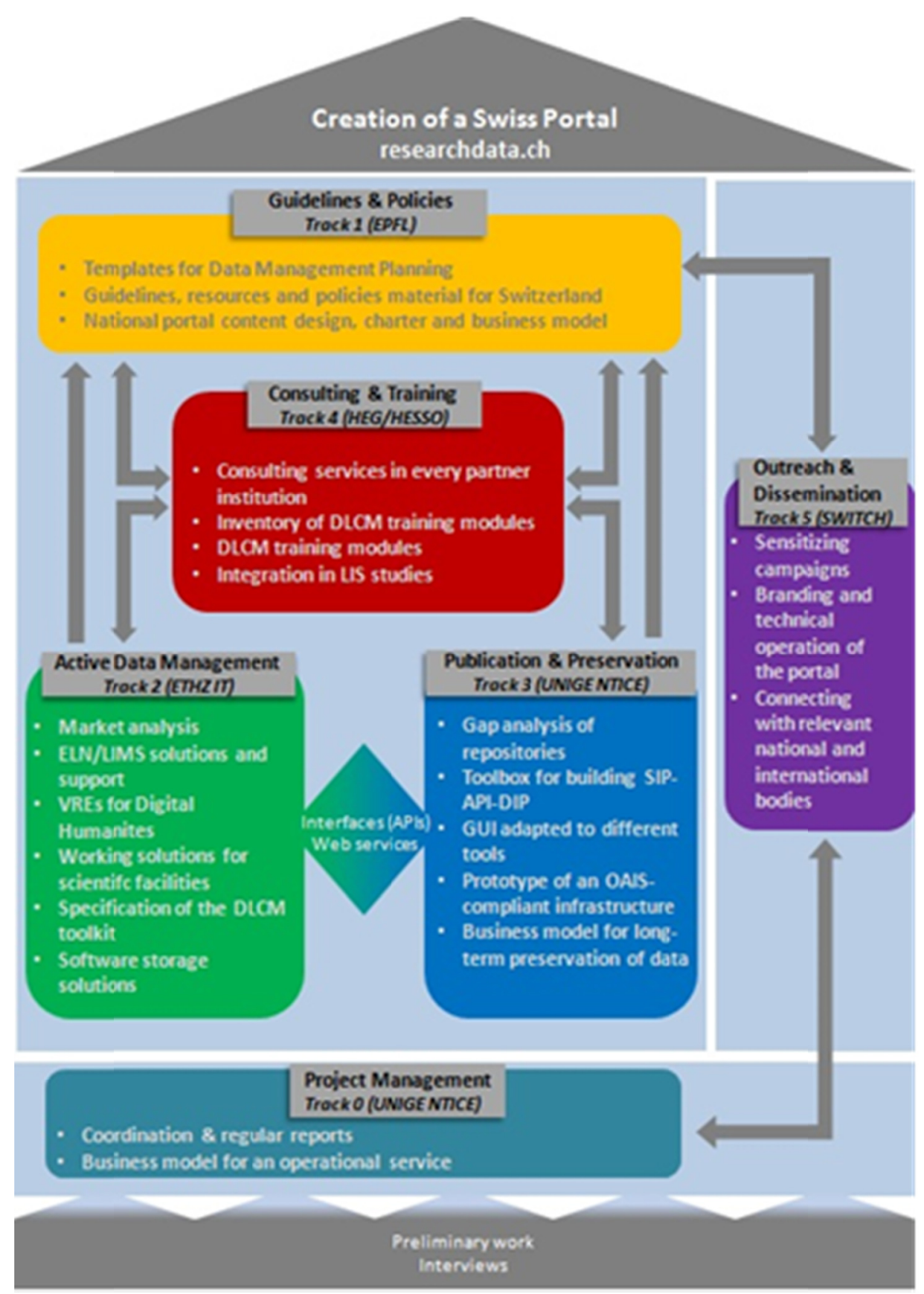

Figure 1: DLCM organisation in 6 tracks 
In the following section, we will present the track 4: one central dimension dealing consulting, training and teaching in the field of research data management (Figure 2).

\section{Consulting, training and teaching for the knowledge transfer in research data management}

The consulting, training and teaching dimension aims to facilitate the creation, centralization and exchange of know-how in the management of research data in each partner institution first and spread this knowledge at national and international level. It is divided into three sets of activities: 4.1) development of advisory and support services in each partner institution (consulting), 4.2) collection and development of training modules (training) and 4.3) integration of teaching modules in the curriculum in information sciences (teaching). Implementation of these activities is carried out in close collaboration with other dimensions and partner institutions of the DLCM project (Figure 2).

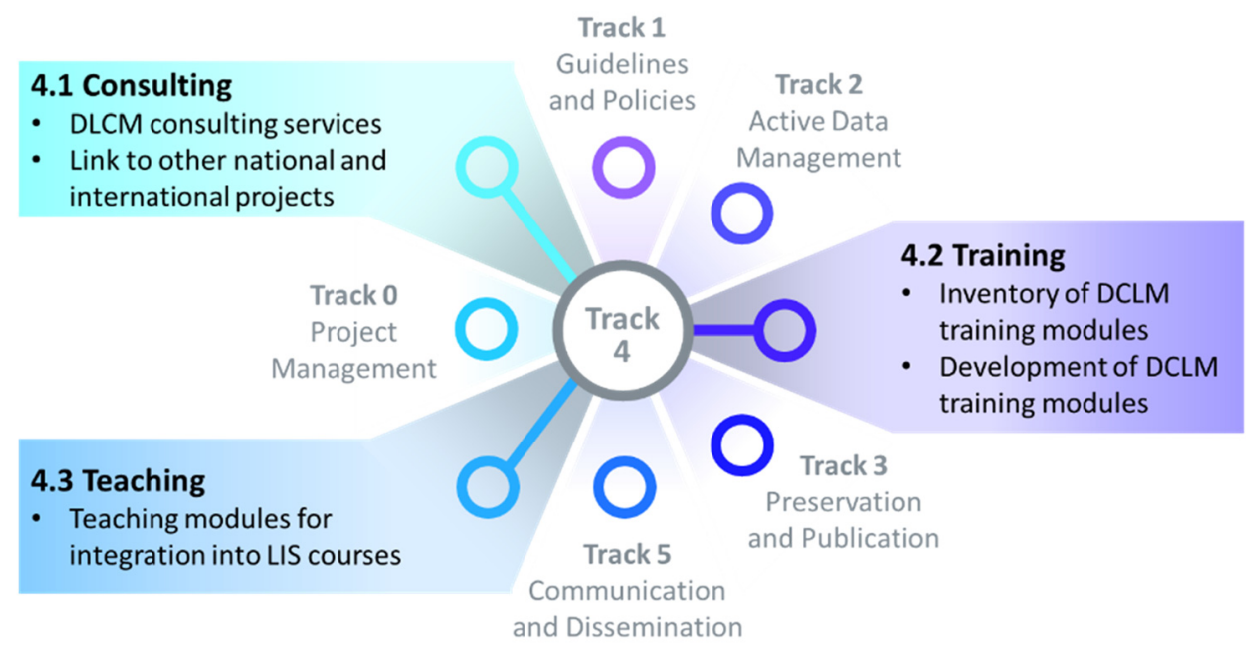

Figure 2: Objectives \& deliverables in Track 4 of DLCM Project

\section{Consulting}

For this theme, we have planned two deliverables: (i) Implementation of consulting services and (ii) coordination between project partners to pool efforts and synergies of similar projects.

The first period focuses mainly on consulting activities, which will be offered to partner institutions and their respective users. The objective is to develop a clearinghouse at the national level using the "DICE+ model" (Digital Copyright in Education) and to offer workshops along with a hub for field expertise. To assume the relevant impact of those two axes (training and consulting), the track 
4 of Project worked on a coordination desk of to guarantee the accessibility and the visibility of those services at national level. Consulting services will be established at the institutional and inter-institutional levels respectively, and will cover all the major steps of DLCM, including processes, tasks and tools. Finally, all these services will be coordinated at interinstitutional level by a central office: Coordination Desk. A pilot of coordination desk is established into the University of Applied Sciences and Arts of Western Switzerland (HES SO). This offers a reel research data national services presence through an extended academic network.

The objective of the DLCM coordination desk is to offer a unique point of contact to all academic institutions for guidance and support on research data management practices. It would do so by having a resource person and teams of focal points and subject-matter experts work together to answer requests from the Swiss research community. The coordination desk will also provide a strong instrument for mobilizing and coordinating the resources needed to achieve this objective. The primary target groups for the coordination desk are researchers and research teams, project managers and administrators, teachers and assistants, as well as students. Secondary target groups are information management professionals and consultants, including librarians, archivists, records managers, IT specialists, etc.

\section{Training}

By training, we mean learning process that allows an individual to acquire the knowledge and skills needed for the professional activity (Swiss DLCM Project, 2017). These training activities, which are intended primarily for users of partner institutes, will be developed with the objective of ensuring an adequate transfer of knowledge and a mastery of the skills and expertise related to the management of research data in the different institutions, irrespective of their size or the complexity of their structures (Makhlouf Shabou \& Echernier, 2016). As shown in Figure 2, the training proposes two deliverables: (i) an inventory of existing training modules; and (ii) the creation of research data training modules.

Two types of training modules are planned: general and advanced. The first, targets to introduce the fields of research data management to beginner scientific communities to coach and help them assuming the basic activities in research data processing. Those introductive modules cover as well principles and method needed for complying high data quality requirements. The advanced modules will address aspects of research data management that have not been covered so far and will be tailored to the specific needs of partner institutions and their respective users.

Added to conception and realization of training modules, two catalogues will be developed: one for research data existing training modules and another for re- 
search data trainers and this on the DLCM project partners and also at the international level.

\section{Teaching}

The third and last set is teaching that refers to academic programs and courses that could be proposed to train-the-trainer who will be future professionals and specialists of research data management (Doctoral seminars, Masters, Bachelors, etc.) (Swiss DLCM Project. 2017). It aims to integrating the knowledge and skills of this project into the master's programs in information sciences. Initially, we propose the promotion of DLCM field to ensure their adoption and rapid application among future professionals, and secondly awareness of students of information science curricula in order to ensure the sustainability of the expertise and the transfer of knowledge for future generations. Since September 2017, the Information Sciences Department of Geneva School of Business Administration of University of Applied Sciences and Arts Western Switzerland offers to the Master of Information Science students a specialization in Data governance. This specialization includes 16 periods (hours) devoted to research data. This was the first implementation step of teaching deliverables. In addition, Master students in this Department have to propose a DMP for their proper Master research. Other courses related to research data are planned to be added into the same programme during the following years.

\section{Conclusion}

The DLCM project creates a real opportunity for developing sustainable and tangible solutions at a national level to implement research data life-cycle management (DLCM) in Switzerland. As mentioned the funding agencies are requiring a research data management ability to ensure the appropriate research data governance of the whole life cycle of researches and also to increase the exploitability of research outcomes. The DLCM offer to researchers the opportunity to exchange valuable materials, tools, methods, infrastructure to be able to acquire the needed knowledge for managing research data from the creation to disposition and the preservation of those data. It specifies the way to perform the capture and creation processes, the techniques and methods to structure and share them, and the requirements of comply standards and good practices preservation. This will indeed reinforce the quality of the work of researchers, since it allows the traceability and the documentation of the research processing. 


\section{References}

Blumer, Eliane; Burgi, Pierre-Yves. Data Life-Cycle Management Project: SUC P2 2015-2018. 17th December 2015. http://www.ressi.ch/num16/article_110 (17th May 2017)

Burgi, Pierre Yves; Blumer, Eliane; Jelicic, André. Research DLCM: Creating the framework for a successful research data management in Switzerland. 13th September 2016. https://prezi.com/jwd2ilsrwruc/research-dlcm/ (19th May 2017)

Makhlouf Shabou, Basma; Burgi, Pierre Yves; Blumer, Eliane; Echernier, Lydie. Le projet DLCM : une approche globale pour une meilleure gouvernance du cycle de vie des données de la recherche en Suisse. Tunis, Colloque international sur les bibliothèques et archives à l'ère des Humanités numériques (CIBAHN), 19 octobre 2016.

Makhlouf Shabou, Basma; Echernier, Lydie. La gouvernance du cycle de vie des données de la recherche en Suisse : transfert \& pérennisation. Montpellier, Journée de la section Aurore “Archiver la recherche : responsabilités partagées", 23 juin 2016.

European Commission - Directorate-General for Research \& Innovation. H2020 Programme: Guidelines on FAIR Data Management in Horizon 2020. 26th July 2016. http://ec.europa.eu/research/participants/data/ref/h2020/grants_manual/hi/oa_pilot/h2020-hioa-data-mgt_en.pdf(19th May 2017)

International Organization for Standardization. Space data and information transfer systems Open archival information system (OAIS) - Reference model. Geneva, ISO 14721, 2012.

Ray, Joyce M. (ed.). Research Data Management: Practical Strategies for Information Professionals. West Lafayette, Purdue University Press, 2014

Swiss DLCM Project. 2017. https://www.dlcm.ch/ (19th May 2017)

UK Data Archive. Create \& manage data: research data lifecycle. 2002-2017. http://www.dataarchive.ac.uk/create-manage/life-cycle (19th May 2017) 